Article

\title{
Application of Heterogeneous Catalysts in the First Steps of the Oseltamivir Synthesis
}

\author{
José M. Fraile * (D) and Carlos J. Saavedra \\ Instituto de Síntesis Química y Catálisis Homogénea (ISQCH), Facultad de Ciencias, \\ CSIC_Universidad de Zaragoza, E-50009 Zaragoza, Spain; carlos_jsf@yahoo.es \\ * Correspondence: jmfraile@unizar.es
}

Received: 17 November 2017; Accepted: 12 December 2017; Published: 17 December 2017

\begin{abstract}
The first steps of oseltamivir synthesis from quinic acid involve acetalization and ester formation. These reactions are catalyzed by either acids or bases, which may be accomplished by heterogeneous catalysts. Sulfonic solids are efficient acid catalysts for acetalization and esterification reactions. Supported tetraalkylammonium hydroxide or 1,5,7-triazabicyclo[4.4.0]dec-5-ene are also efficient base catalysts for lactone alcoholysis and in this work, these catalysts have been applied in two alternative synthetic routes that lead to oseltamivir. The classical route consists of an acetalization, followed by a lactonization, and then a lactone alcoholysis. This achieves a $66 \%$ isolated yield. The alternative route consists of esterification followed by acetalization and is only efficient when an acetone acetal is used.
\end{abstract}

Keywords: heterogeneous catalysis; acetalization; lactonization; esterification; sulfonic solids; oseltamivir

\section{Introduction}

Pharmaceutical molecules are quintessentially specialty chemicals with structural complexity that require multistep synthetic routes [1]. In addition to atom economy, other parameters such as step [2,3] and pot [4] economy have to be considered in assessments of synthetic routes. The option to carry out multistep chemical transformations in one pot would be of great interest for the synthesis of pharmaceuticals [5]. Heterogeneous catalysts are viable options [6] as multifunctional heterogeneous catalysts and furthermore, different solids can be used to support sites that would otherwise be mutually incompatible in one reaction system [7].

Oseltamivir is one of the most important anti-influenza drugs, and has interesting synthetic approaches, with various routes having from four to 25 steps [8]. The highest overall yield and step economy is provided by a route beginning with (-)-shikimic acid [9] (Scheme 1), which is a natural product obtained from the Chinese star anise (Illicium verum). Hence, its availability and price generate a bottleneck for this synthesis, and in fact, the shortage of Tamiflu in 2005 during the avian flu pandemic is attributed to this problem.

Intensive research has been carried out to develop total synthesis of oseltamivir using commercially available starting materials. In some cases, the synthetic route starts from cyclic materials, as in Shibasaki's [10] and Zutter's [11] methods, in which one of the key steps is the desymmetrization of a meso intermediate, or Trost's synthesis [12], using an asymmetric allylic alkylation as key step. In other cases, one of the key steps is the formation of the cyclohexene ring, for example through an asymmetric Diels-Alder reaction, as in Corey's [13] and Fukuyama's [14] methods. In all cases, the synthetic pathway involves several (nine to 14) steps. Some synthetic methods from sugars have been described $[15,16]$, and are even more complicated. Very recently, the construction of the oseltamivir ring has been described in a three-component reaction system using highly efficient asymmetric organocatalysis [17]. 


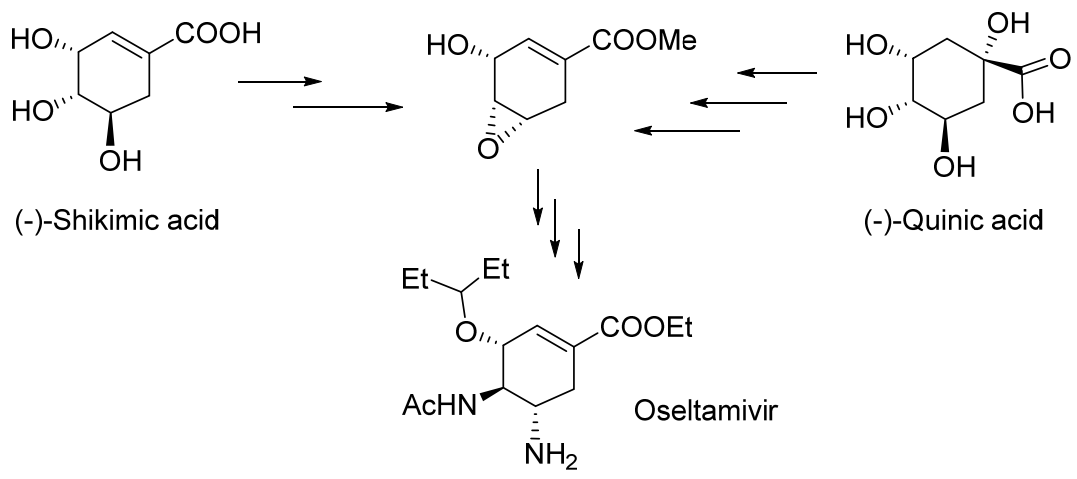

Scheme 1. General routes to oseltamivir from (-)-shikimic and (-)-quinic acids.

For the moment, the most scalable route to oseltamivir involves (-)-quinic acid as the starting material (Scheme 1), as it shares a good number of steps with the well-known shikimic acid route. The first step of the oseltamivir syntheses, starting from (-)-quinic acid (1) [18,19], consists of the acetalization of the two cis hydroxyl groups in positions 3 and 4 with acetone, with concomitant lactonization of the carboxylic group and the cis hydroxyl at carbon 5, catalyzed by $p$-toluenesulfonic acid, leading to the acetal-lactone (2a) (Scheme 2). The lactone ring is then opened by a reaction with $\mathrm{EtONa} / \mathrm{EtOH}$, to obtain the acetal-ester (3ab). Notably, there is a pent-3-yl group in the final product that requires a transacetalization step. A weak point of this route is the use of dimethyl acetonide [20], and this could be circumvented if the acetalization were carried out directly with pentan-3-one to get $(\mathbf{2} \mathbf{b})$, and subsequently ( $\mathbf{3} \mathbf{b} \mathbf{b})$ as the acetal-ester product (Scheme 2). Alternatively, there could be a viable route via an initial esterification step, leading to the ethyl quinate (4b), with subsequent acetalization (Scheme 2).

In this manuscript, both alternatives starting from (-)-quinic acid (referred to henceforth as "quinic acid") will be studied using heterogeneous catalysts, as well as the possibility to carry out the transformation in one pot. As the methyl ester has been also described in other synthetic pathways, the series of methyl esters (3aa, $\mathbf{4 a}$ ) will be also explored.

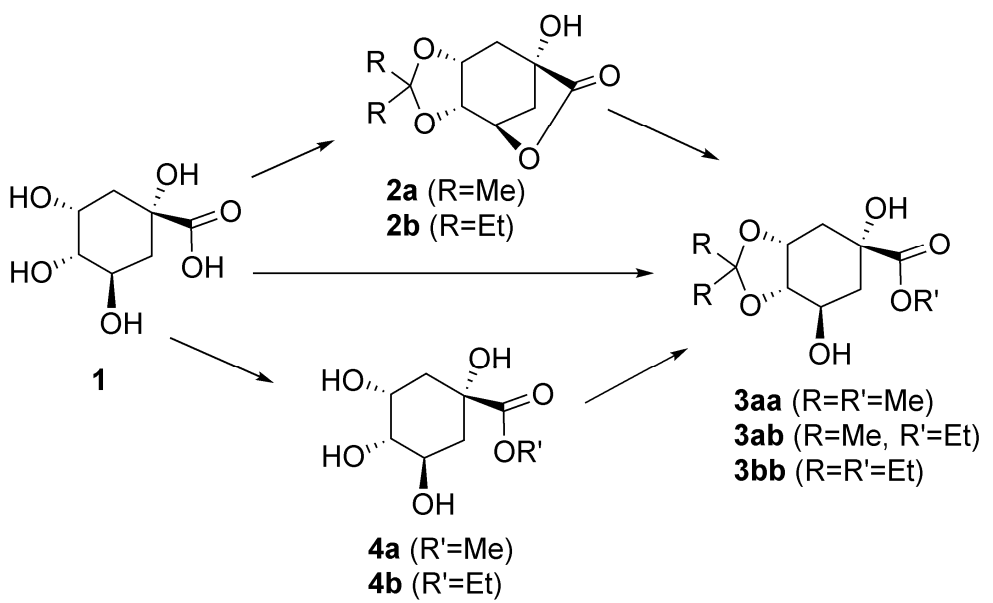

Scheme 2. Possible routes from (-)-quinic acid to the acetal-esters (3). 


\section{Results and Discussion}

\subsection{Single Step One: Acetal Formation from Quinic Acid}

The first step described in the Gilead [18] and Hoffmann-La Roche $[9,19]$ routes is the acetalization of quinic acid with 2,2-dimethoxypropane in acetone catalyzed by $p$-toluenesulfonic acid (PTSA) (Scheme 3).<smiles>[R]C(=O)OC1(O)C[C@H](O)[C@H](O)[C@@H]1O</smiles>

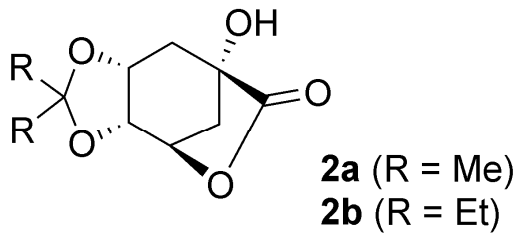

Scheme 3. Acetalization of (-)-quinic acid.

Many sulfonic solids have been described as catalysts for acid-catalyzed procedures [21-23], and several of them were chosen (Figure 1) as potentially interesting alternatives for PTSA:

- Amberlyst IR-15 [24]: macroreticular sulfonated polystyrene-divinylbenzene with $20 \%$ cross-linking degree.

- Deloxan ASP I/9 [25]: alkyl sulfonic polysiloxane.

- SAC-13 [26]: nafion-silica composite, with perfluoroalkyl sulfonic groups.

- sulfonated hydrothermal carbon (SHTC): prepared from glucose under mild conditions and sulfonated with sulfuric acid [27] that contains arylsulfonic groups and has shown improved activity in different esterification reactions [28,29].<smiles>CCCC(CC)c1ccc(C(CCC)C(C)(C)CC(C)C(C)(C)c2ccc(S(=O)(=O)O)cc2)cc1</smiles><smiles>O=S(=O)(O)CCC[Si](O[SiH3])(O[SiH3])O[SiH3]</smiles><smiles>CC(C)C(F)(F)C(F)(F)C(F)(F)C(F)(F)S(=O)(=O)O</smiles>

SAC-13

Deloxan ASP I/9

Figure 1. Sulfonic solids used as acid catalysts.

The results obtained with all the sulfonic catalysts are collected in Table 1.

With 3.5 eq of 2,2-dimethoxypropane (DMP) heated at reflux in acetone, all the solid catalysts, with the exception of Amberlyst IR-15, led to yields of the acetal-lactone 2a higher (86-91\%, entries 3, 7 and 9) than that obtained with PTSA ( $83 \%$, entry 1 ). The reaction is significantly slower in the absence of DMP (entries 4, 8 and 10), or with DMP at room temperature (entry 11) or in a solvent other than acetone (entry 12).

In the case of pentan-3-one, the dimethyl acetal is not commercially available and the reactions that lead to $\mathbf{2} \mathbf{b}$ were carried out in the ketone heated at reflux. Given its higher boiling point, the reaction was faster and yields of over 90\% were obtained after only $24 \mathrm{~h}$ (entries 13 and 14). 
Table 1. Results of the acetalization of quinic acid. ${ }^{1}$

\begin{tabular}{|c|c|c|c|c|c|c|}
\hline Entry & Ketone & Catalyst $^{2}$ & $\mathrm{~T}\left({ }^{\circ} \mathrm{C}\right)$ & DMP $^{3}$ & Time (h) & Yield (\%) \\
\hline 1 & Acetone & PTSA & 56 & Yes & 3 & 83 \\
\hline \multirow[t]{2}{*}{2} & $(\mathrm{R}=\mathrm{Me})$ & IR-15 & 56 & Yes & 3 & 48 \\
\hline & & & & & 48 & 73 \\
\hline 3 & & Deloxan & 56 & Yes & 3 & 91 \\
\hline 4 & & & 56 & No & 3 & 10 \\
\hline 5 & & & 25 & Yes & 68 & 63 \\
\hline 6 & & & 66 & Yes $^{4}$ & 3 & 11 \\
\hline 7 & & SAC-13 & 56 & Yes & 3 & 86 \\
\hline \multirow[t]{3}{*}{8} & & & 56 & No & 3 & 15 \\
\hline & & & & & 24 & 40 \\
\hline & & & & & 72 & 64 \\
\hline 9 & & SHTC & 56 & Yes & 3 & $90^{5}$ \\
\hline \multirow[t]{3}{*}{10} & & & 56 & No & 3 & 9 \\
\hline & & & & & 24 & 64 \\
\hline & & & & & 48 & 80 \\
\hline 11 & & & 25 & Yes & 24 & 82 \\
\hline 12 & & & 66 & Yes $^{4}$ & 3 & 61 \\
\hline 13 & Pentan-3-one & Deloxan & 101 & No & 24 & 100 \\
\hline \multirow[t]{2}{*}{14} & $(\mathrm{R}=\mathrm{Et})$ & SHTC & 101 & No & 24 & 91 \\
\hline & & & & & 48 & 100 \\
\hline
\end{tabular}

${ }^{1}$ Reaction conditions: quinic acid $(1 \mathrm{mmol})$, catalyst $(0.01 \mathrm{mmol})$, ketone $(4 \mathrm{~mL}){ }^{2}$ PTSA: $p$-toluenesulfonic acid; SHTC: sulfonated hydrothermal carbon; ${ }^{3}$ DMP: addition of 2,2-dimethoxypropane (3.5 mmol);

${ }^{4}$ with tetrahydrofuran $(4 \mathrm{~mL})$ as solvent instead of acetone; ${ }^{5}$ average yield of two experiments.

\subsection{Single Step Two: Lactone Alcoholysis}

The second step is the lactone alcoholysis to give the acetal-ester 3 (Scheme 4). This reaction is in fact a transesterification, which could be catalyzed by acids or bases, and the two types of solid catalysts were tested.

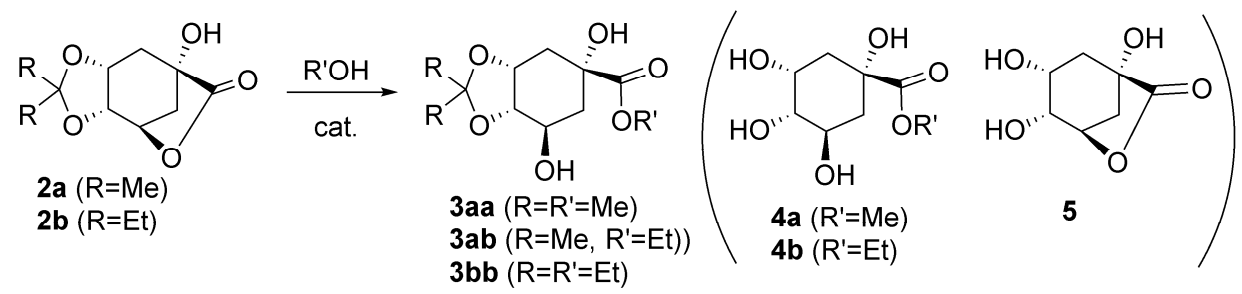

Scheme 4. Alcoholysis of acetal-lactones 2.

In the two acid-catalyzed reactions with ethanol (Table 2), the lactone ethanolysis was quite efficient, with yields of esters around $74 \%-77 \%$ (entries 1 and 3 ), but unfortunately, the side transacetalization reaction was also very efficient, and the main product was in both cases the ethyl quinate $4 \mathbf{b}$, with a small amount of lactone 5 [30]. At room temperature (entries 2 and 4), the reaction was very slow.

Three heterogeneous basic catalysts were tested (Figure 2): Amberlite IRA-400 [31] (quaternary ammonium hydroxide) and 1,5,7-triazabicyclo[4.4.0]dec-5-ene (TBD), supported on either polystyrene (TBD-PS [32]) or silica (TBD-SiO 2 [33]). Their activities were compared with tetramethylammonium hydroxide and TBD, which are the homogeneous counterparts. Only the lactone $2 \mathrm{a}$ and the ethyl ester $\mathbf{3 a b}$ were detectable in the reaction mixtures. While heated at reflux in ethanol, the $\mathbf{2 a} / \mathbf{3 a b}$ ratio was around 40:60, which seems to be the equilibrium position under those conditions. At lower temperature, the reaction is not so easily reversible, and $86 \%$ yield can be obtained with TBD-PS after only $24 \mathrm{~h}$ at $0{ }^{\circ} \mathrm{C}$ (entry 10). The homogeneous catalysts (entries 11-14) lead to similar or worse results, 
showing the positive effect of immobilization on the activity, together with the simple work-up of the reaction mixture when using heterogeneous catalysts. In the case of $3 \mathbf{b b}, 84 \%$ yield can be also obtained with TBD-PS at $0{ }^{\circ} \mathrm{C}$ (entry 17). Finally, the methyl ester 3aa can also be obtained from 2a and methanol with very high yield (96\%) at $0{ }^{\circ} \mathrm{C}$ after $48 \mathrm{~h}$ (entry 18).

Table 2. Results of the alcoholysis of acetal-lactones 2. ${ }^{1}$

\begin{tabular}{|c|c|c|c|c|c|c|c|c|}
\hline \multirow{2}{*}{ Entry } & \multirow{2}{*}{ Reaction } & \multirow{2}{*}{ Catalyst } & \multirow{2}{*}{$\frac{\mathrm{T}}{\left({ }^{\circ} \mathrm{C}\right)}$} & \multirow{2}{*}{$\begin{array}{c}\text { Time } \\
\text { (h) }\end{array}$} & \multicolumn{4}{|c|}{ Yield (\%) } \\
\hline & & & & & 2 & 3 & 4 & 5 \\
\hline 1 & $2 a+E t O H$ & SAC-13 & 78 & 24 & 13 & 1 & 76 & 10 \\
\hline 2 & & & 25 & 24 & 87 & 0 & 6 & 7 \\
\hline 3 & & SHTC & 78 & 24 & 17 & 2 & 72 & 9 \\
\hline 4 & & & 25 & 24 & 82 & 0 & 9 & 9 \\
\hline 5 & & IRA-400 & 78 & 5 & 42 & 58 & - & - \\
\hline 6 & & $\mathrm{TBD}_{-} \mathrm{SiO}_{2}$ & 78 & 4 & 40 & 60 & - & - \\
\hline \multirow[t]{2}{*}{7} & & & 25 & 4 & 69 & 31 & - & - \\
\hline & & & & 19 & 45 & 55 & - & - \\
\hline 8 & & & -20 & 48 & 21 & 79 & - & - \\
\hline 9 & & TBD-PS & 78 & 4 & 36 & 64 & - & - \\
\hline \multirow[t]{3}{*}{10} & & & 0 & 4 & 60 & 40 & - & - \\
\hline & & & & 24 & 14 & 86 & - & - \\
\hline & & & & 48 & 10 & $90^{2}$ & - & - \\
\hline 11 & & $\mathrm{Me}_{4} \mathrm{NOH}$ & 78 & 24 & 39 & 61 & - & - \\
\hline \multirow[t]{2}{*}{12} & & & 0 & 24 & 30 & 70 & - & - \\
\hline & & & & 48 & 30 & 70 & - & - \\
\hline 13 & & TBD & 78 & 24 & 42 & 58 & - & - \\
\hline \multirow[t]{2}{*}{14} & & & 0 & 24 & 42 & 58 & - & - \\
\hline & & & & 48 & 43 & 57 & - & - \\
\hline 15 & $2 \mathbf{b}+\mathrm{EtOH}$ & TBD-SiO 2 & 78 & 4 & 48 & 52 & - & - \\
\hline 16 & & TBD-PS & 78 & 4 & 44 & 56 & - & - \\
\hline \multirow[t]{3}{*}{17} & & & 0 & 4 & 29 & 71 & - & - \\
\hline & & & & 24 & 16 & 84 & - & - \\
\hline & & & & 48 & 14 & $86^{2}$ & - & - \\
\hline \multirow[t]{2}{*}{18} & $\mathbf{2 a}+\mathrm{MeOH}$ & TBD-PS & 0 & 24 & 31 & 69 & - & - \\
\hline & & & & 48 & 4 & $96^{2}$ & - & - \\
\hline
\end{tabular}

${ }^{1}$ Reaction conditions: lactone $2(1 \mathrm{mmol})$, alcohol $(4 \mathrm{~mL})$ and catalyst $(0.01 \mathrm{mmol}$ of acid or $0.1 \mathrm{mmol}$ of base);

2 average yields of two experiments.

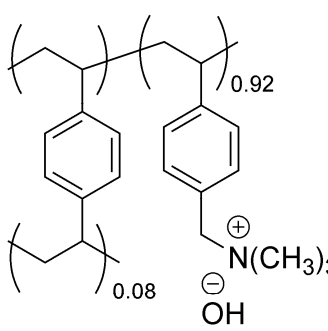

Amberlite IRA-400

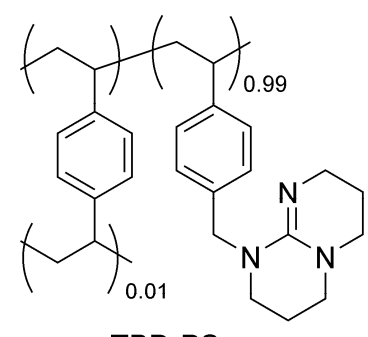

TBD-PS<smiles>CC(C)([SiH3])CCCN1CCCN2CCCN=C21</smiles>

TBD-SiO 2

Figure 2. Solids used as base catalysts.

\subsection{One-Pot Acetalization and Lactone Alcoholysis: Single Acid Catalyst}

In spite of the transacetalization problems detected with acid catalysts, the direct one-pot synthesis of acetal-esters 3 (Scheme 5) was tried with the sulfonic solids, using 2,2-dimethoxypropane in a 1:1 mixture $(v / v)$ of acetone and the corresponding alcohol (Table 3). 


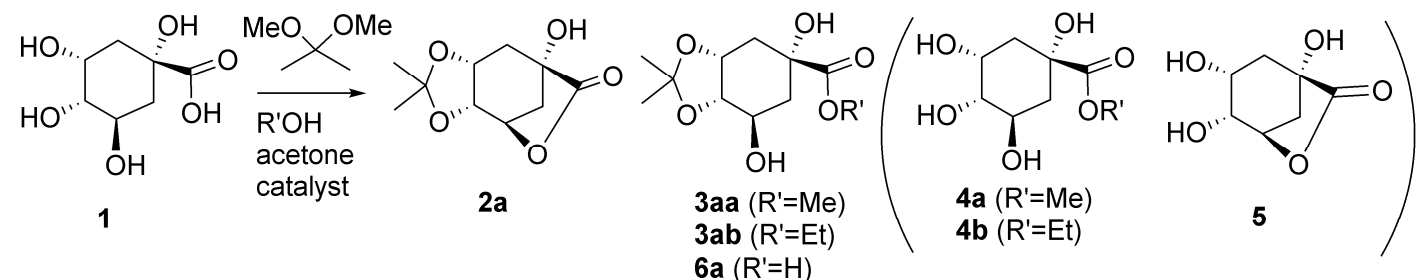

Scheme 5. One-step formation of dimethyl acetal and ester from quinic acid using 2,2-dimethoxypropane.

Table 3. Results of the one-step formation of dimethyl acetal and ester from quinic acid. ${ }^{1}$

\begin{tabular}{cccccccc}
\hline \multirow{2}{*}{ Entry } & \multirow{2}{*}{ Alcohol } & \multirow{2}{*}{ Catalyst } & \multicolumn{5}{c}{ Yield (\%) } \\
\cline { 3 - 7 } & & $\mathbf{2 a}$ & $\mathbf{3}$ & $\mathbf{4}$ & $\mathbf{5}$ & $\mathbf{6}$ \\
\hline 1 & \multirow{2}{*}{ EtOH } & Deloxan $^{2}$ & 56 & 8 & 9 & 7 & 20 \\
2 & & IR-15 & 54 & 0 & 32 & 6 & 8 \\
3 & & SAC-13 & 38 & 3 & 38 & 10 & 11 \\
4 & & SHTC & 46 & 0 & 24 & 12 & $3^{3}$ \\
5 & \multirow{2}{*}{$\mathrm{MeOH}$} & Deloxan & 41 & 25 & 23 & 7 & 4 \\
6 & & IR-15 & 35 & 9 & 45 & 10 & 1 \\
7 & & SAC-13 & 38 & 26 & 26 & 7 & 3 \\
8 & & SHTC & 39 & 0 & 49 & 12 & 0 \\
\hline
\end{tabular}

1 Reaction conditions: quinic acid $(1 \mathrm{mmol}), 2$ 2-dimethoxypropane $(3.5 \mathrm{mmol})$, catalyst $(0.01 \mathrm{mmol})$ in acetone/alcohol $(4 \mathrm{~mL}, 1: 1 \mathrm{v} / \mathrm{v})$, heated at reflux, $24 \mathrm{~h} ;{ }^{2}$ average yields of two experiments; ${ }^{3}$ the remaining $15 \%$ corresponds to unconverted quinic acid.

The reaction with ethanol led to five reaction products, two lactones in the form of acetal (2a) and free hydroxyls (5), two ethyl esters with acetal (3ab) and free quinate (4b), as well as the quinic acid acetal (6a). Total conversion of quinic acid was obtained in most cases, but the product distribution was quite different depending on the catalyst. However, the acetal-ester $3 \mathbf{a b}$, the desired product, was not obtained with a significant yield. On the contrary, ethyl quinate $4 \mathrm{~b}$ was the major product because of the transacetalization of $\mathbf{2 a}$ with ethanol in the presence of the acid catalyst.

Methanol is much more reactive than ethanol and consequently, the results are quite different. In fact, the yield of the desired acetal-ester 3aa was significant, around 25\% with both Deloxan and SAC-13 (entries 5 and 7), although the yield of free ester $4 \mathbf{a}$ was also important in all the cases.

Finally, the reaction of quinic acid in a 1:1 mixture of ethanol and pentan-3-one (Scheme 6) was tried with the same acid catalysts (Table 4). The yields of the compounds with the acetal group ( $\mathbf{3 b b}$ and 6) were very low, showing the lower stability of the pentanone acetal. In view of the problems associated with the use of acid catalysts in the alcoholysis step, the sequential acetalization followed by alcoholysis was tested with two different catalysts.

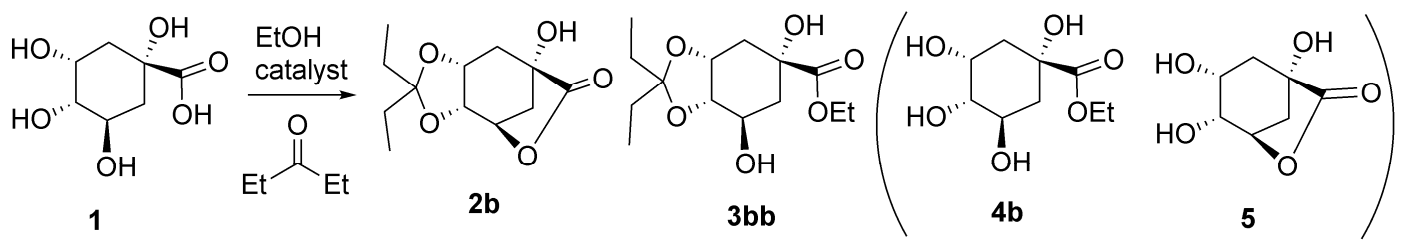

Scheme 6. One-step formation of diethyl acetal and ethyl ester from quinic acid using pentan-3-one and ethanol. 
Table 4. Results of the one-step formation of diethyl acetal and ethyl ester from quinic acid. ${ }^{1}$

\begin{tabular}{ccccc}
\hline \multirow{2}{*}{ Catalyst } & \multicolumn{5}{c}{ Yield (\%) } \\
\cline { 2 - 5 } & $\mathbf{2 b}$ & $\mathbf{3 b b}$ & $\mathbf{4 b}$ & $\mathbf{5}$ \\
\hline Deloxan & 27 & 3 & 43 & 24 \\
IR-15 & 34 & 2 & 47 & 17 \\
SAC-13 & 20 & 10 & 53 & 17 \\
SHTC & 67 & 0 & 29 & 4
\end{tabular}

${ }^{1}$ Reaction conditions: quinic acid $(1 \mathrm{mmol})$, catalyst $(0.01 \mathrm{mmol})$ in pentan-3-one/ethanol $(4 \mathrm{~mL}, 1: 1 \mathrm{v} / \mathrm{v})$, heated at reflux, $24 \mathrm{~h}$.

\subsection{One-Pot Sequential Process with One Acid and One Base Catalyst: Acetalization and Lactone Alcoholysis}

In the sequential process (Scheme 7), the first acetalization reaction was carried out under the optimal conditions determined in the individual test, and once the reaction mixture was cooled at $0{ }^{\circ} \mathrm{C}$, the basic catalyst TBD-PS and ethanol were added. As can be seen in the results (Table 5), the alcoholysis is less efficient under these new conditions. A significant amount of acetal-lactone 2a (53\% with Deloxan, entry 1, and 38\% with SHTC, entry 2) remained unreacted even after $48 \mathrm{~h}$, and the conversion of $\mathbf{2} \mathbf{b}$ was even lower under the same conditions (entries 5 and 8), giving $13 \%$ of acetal-ester $\mathbf{3 b b}$ as the best result (entry 8 ). The filtration of the acid catalyst before addition of the basic catalyst and ethanol (entry 3) did not improve the results, demonstrating that the presence of the acid catalyst was not the reason for this lower efficiency. The combination of a ketone and a base catalyst may produce an aldol condensation as side reaction, as already detected in previous work [7].

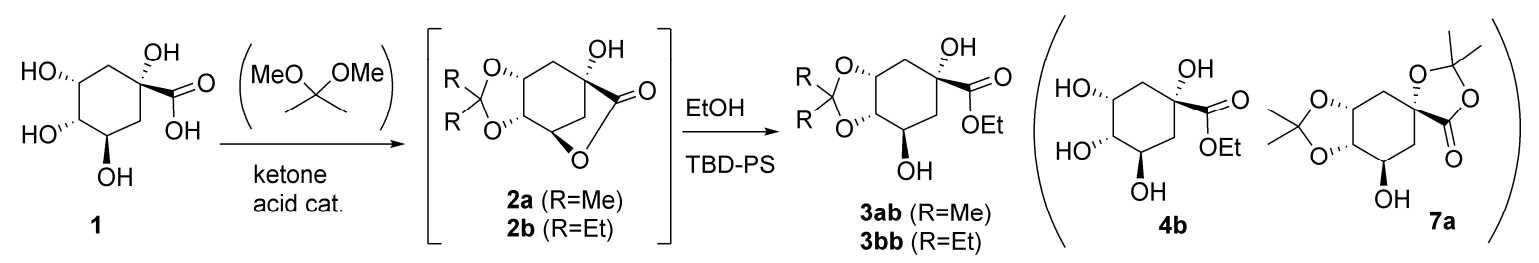

Scheme 7. One-pot sequential acetalization of quinic acid and lactone alcoholysis.

Furthermore, about one-half of the converted 2a was transformed to a previously undetected new product, which was identified as the compound 7 (entries 1-3), which must arise from the simultaneous presence of acetone/DMP and a basic catalyst. In fact, when the acetone/DMP mixture was evaporated prior to the addition of ethanol and TBD-PS (entry 4), the conversion of acetal-lactone 2a was significantly improved and the compound 7 was not obtained. The simultaneous presence of the acid catalyst and ethanol did produce a partial transacetalization to the ethyl quinate $4 \mathrm{~b}$. The partial transacetalization was also observed when pentan-3-one was evaporated before the addition of TBD-PS and ethanol (entry 6). In view of the incompatibility of reagents and catalysts of the two reaction steps, the acid catalyst was filtered and pentan-3-one was evaporated before the addition of ethanol and TBD-PS to the crude mixture (entries 7 and 9). As expected, the reaction selectively formed the acetal-ester $\mathbf{3 b b}$, with up to a $76 \%$ yield after $96 \mathrm{~h}$ (entry 9), showing that pure acetal-lactone $\mathbf{2 b}$ behaves much better than the crude one for the base-catalyzed lactone alcoholysis. 
Table 5. Results of the one-pot sequential acetalization of quinic acid and lactone alcoholysis. ${ }^{1}$

\begin{tabular}{|c|c|c|c|c|c|c|c|c|}
\hline \multirow{2}{*}{ Entry } & \multirow{2}{*}{ Ketone } & \multirow{2}{*}{ Acid Catalyst } & \multicolumn{2}{|c|}{ Time (h) } & \multicolumn{4}{|c|}{ Yield (\%) } \\
\hline & & & 1st & 2nd & 2 & 3 & $4 b$ & $7 \mathbf{a}$ \\
\hline \multirow[t]{2}{*}{1} & Acetone & Deloxan & 4 & 24 & 54 & 21 & - & 19 \\
\hline & & & & 48 & 53 & 26 & - & 16 \\
\hline \multirow[t]{2}{*}{2} & & SHTC & 4 & 24 & 41 & 28 & - & $31^{2}$ \\
\hline & & & & 48 & 38 & 32 & - & 30 \\
\hline \multirow[t]{2}{*}{3} & & SHTC $^{3}$ & 4 & 24 & 48 & 23 & - & 28 \\
\hline & & & & 120 & 25 & 46 & - & 29 \\
\hline \multirow[t]{2}{*}{4} & & SHTC $^{4}$ & 4 & 24 & 19 & 65 & 16 & - \\
\hline & & & & 48 & 11 & 49 & 40 & - \\
\hline \multirow[t]{2}{*}{5} & Pentan-3-one & Deloxan & 24 & 24 & 100 & - & - & - \\
\hline & & & & 48 & 85 & - & $7^{5}$ & - \\
\hline 6 & & Deloxan 4 & 24 & 24 & 53 & 23 & 24 & - \\
\hline \multirow[t]{2}{*}{7} & & Deloxan 6 & 24 & 24 & 47 & 53 & - & - \\
\hline & & & & 48 & 35 & 65 & - & - \\
\hline \multirow[t]{2}{*}{8} & & SHTC & 48 & 24 & 87 & 13 & - & - \\
\hline & & & & 120 & 87 & 13 & - & - \\
\hline \multirow[t]{3}{*}{9} & & SHTC $^{5}$ & 48 & 24 & 46 & 54 & - & - \\
\hline & & & & 48 & 29 & 71 & - & - \\
\hline & & & & 96 & 24 & 76 & - & - \\
\hline
\end{tabular}

${ }^{1}$ Reaction conditions: quinic acid $(1 \mathrm{mmol})$, acid catalyst $(0.01 \mathrm{mmol})$, ketone $(4 \mathrm{~mL})$, at reflux. In the case of the reaction with acetone, 2,2-dimethoxypropane $(3.5 \mathrm{mmol})$ was also added. The second reaction was carried out at $0{ }^{\circ} \mathrm{C}$ after addition of TBD-PS $(0.1 \mathrm{mmol})$ and ethanol $(4 \mathrm{~mL}) ;^{2}$ average yields of two experiments; ${ }^{3}$ the acid catalyst is filtered before adding ethanol and TBS-PS; ${ }^{4}$ the ketone is evaporated under vacuum before adding ethanol and TBS-PS; ${ }^{5}$ lactone 5 was also obtained in $8 \%{ }^{6}$ the acid catalyst is filtered and the pentan-3-one is evaporated under vacuum before adding ethanol and TBS-PS.

\subsection{Single Step Three: Esterification of Quinic Acid}

In view of the problems encountered in the sequential process of acetalization followed by alcoholysis, another strategy was conceived by changing the sequence order. This new sequence consists of an initial esterification of quinic acid to the corresponding quinate 4 (Scheme 8 ) and then the acetalization of this ester. Again, the main advantage would be the possibility of using a single acid catalyst and thus, the individual esterification step was studied (Table 6).

Both ethyl quinate $\mathbf{4 b}$ and lactone 5 were obtained in ethanol (entries 1-4), but the lactone underwent a slow acid-catalyzed alcoholysis, leading to more than a $90 \%$ yield of ethyl quinate 4 with SHTC (entry 4). The higher reactivity of methanol led to a faster alcoholysis reaction and, in general, higher methyl ester (4a) yields were obtained in shorter reaction times (entries 5-6).

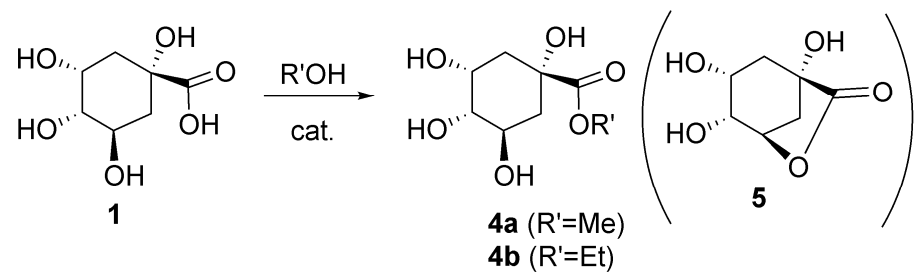

Scheme 8. Esterification of quinic acid. 
Table 6. Results of the esterification of quinic acid with ethanol or methanol. ${ }^{1}$

\begin{tabular}{cccccc}
\hline \multirow{2}{*}{ Entry } & \multirow{2}{*}{ Alcohol } & Catalyst & Time (h) & \multicolumn{2}{c}{ Yield (\%) } \\
\cline { 4 - 6 } & & & $\mathbf{4}$ & $\mathbf{5}$ \\
\hline 1 & EtOH & Deloxan & 3 & 19 & 12 \\
& & & 72 & $25^{2}$ \\
& & 48 & 81 & 19 \\
& & 68 & 87 & 13 \\
2 & & Deloxan $^{3}$ & 24 & 83 & 17 \\
3 & & SAC-13 & 24 & 65 & 22 \\
4 & & SHTC & 24 & 82 & 9 \\
& & & 48 & 90 & 10 \\
5 & & & 72 & 93 & 7 \\
6 & \multirow{2}{*}{ MeOH } & Deloxan & 48 & 94 & 6 \\
& & SHTC & 24 & 93 & 7 \\
\hline
\end{tabular}

${ }^{1}$ Reaction conditions: quinic acid $1(1 \mathrm{mmol})$, ethanol or methanol $(4 \mathrm{~mL})$, and catalyst $(0.01 \mathrm{mmol})$ heated at reflux;

2 average yields of two experiments; ${ }^{3} 0.02$ mmol of catalyst.

\subsection{Sequential Process with One or Two Acid Catalysts: Esterification and Acetalization}

The sequence of esterification with ethanol followed by acetalization was then tried with both acetone and pentan-3-one (Scheme 9). In the first case, DMP was used to efficiently promote the acetalization reaction. Two efficient catalysts for the direct esterification of quinic acid with ethanol-Deloxan and SHTC - were chosen to act as the single catalyst for both reactions or to be combined as catalysts for the first and second reactions. The results are gathered in Table 7.

The combination of Deloxan for the esterification with ethanol, and SHTC for acetalization with acetone and DMP, was tested (entry 1). A long reaction time was used in the first reaction to reach the highest conversion of quinic acid, whereas room temperature and moderate time was used for the second reaction. The acetalization of ethyl quinate $4 \mathrm{~b}$ was slower than acetalization of quinic acid. In fact, after $24 \mathrm{~h}, 13 \%$ of $\mathbf{4 b}$ remained unconverted. Moreover, the acetal-lactone $\mathbf{2} \mathbf{a}$ was also obtained (up to $24 \%$ yield), indicating that lactonization can also be produced from the ester. Longer reaction times did not change the result. In the absence of DMP, the acetalization was slower (entry 2), but the lactonization occurred in a similar ratio. The use of SHTC as the only catalyst for both reactions improves both conversion and selectivity to $3 \mathbf{a b}$ (74\% yield, entry 4$)$, but the best result was obtained with Deloxan as the only catalyst (entry 3), with almost complete conversion of $\mathbf{4 b}$ and $83 \%$ yield of the acetal-ester $3 \mathbf{a b}$.

When acetalization was carried out at higher temperature (acetone reflux), conversion was higher but selectivity was much lower due to an extensive lactonization (entries 5 and 6). On the contrary, a decrease in reaction temperature to $0{ }^{\circ} \mathrm{C}$ (entries 7 and 8) improves the selectivity with respect to the desired acetal-ester when SHTC is the acetalization catalyst, but $83 \%$ was the maximum yield (entry 7) obtained in any case.

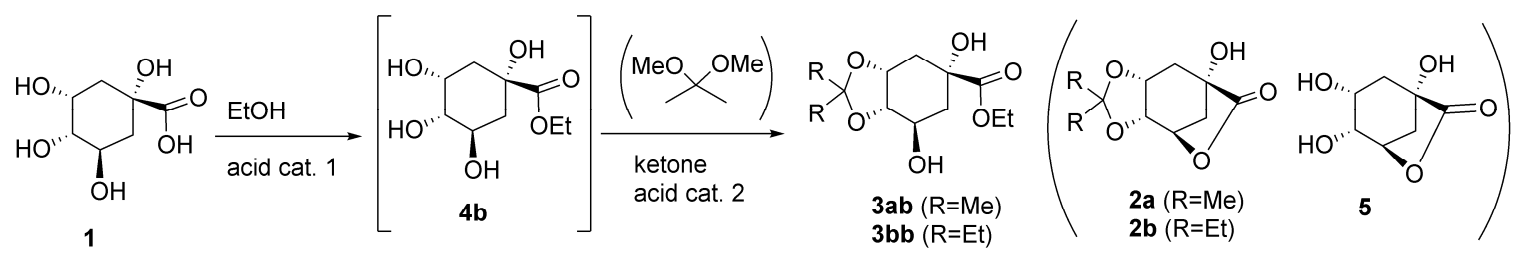

Scheme 9. Sequential esterification and acetalization of quinic acid. 
Table 7. Sequential esterification and acetalization of quinic acid with two acid catalysts. ${ }^{1}$

\begin{tabular}{|c|c|c|c|c|c|c|c|c|c|c|}
\hline \multirow{2}{*}{ Entry } & \multirow{2}{*}{$\begin{array}{c}\text { Acid } \\
\text { catalyst } 1\end{array}$} & \multirow{2}{*}{$\begin{array}{l}\text { Esterification } \\
\text { Time (h) }\end{array}$} & \multirow{2}{*}{$\begin{array}{c}\text { Acid } \\
\text { catalyst } 2\end{array}$} & \multirow{2}{*}{ Ketone } & \multicolumn{2}{|c|}{ Acetalization } & \multicolumn{4}{|c|}{ Yield (\%) } \\
\hline & & & & & $\mathrm{T}\left({ }^{\circ} \mathrm{C}\right)$ & Time (h) & $4 \mathrm{~b}$ & 3 & 2 & 5 \\
\hline \multirow[t]{2}{*}{1} & Deloxan & 70 & SHTC & Acetone & 25 & 15 & 29 & 56 & 15 & 0 \\
\hline & & & & & & 24 & 13 & 63 & 24 & 0 \\
\hline 2 & Deloxan & 70 & SHTC & Acetone $^{2}$ & 25 & 40 & 27 & 57 & 16 & 0 \\
\hline 3 & Deloxan $^{3}$ & 70 & - & Acetone & 25 & 40 & 3 & 83 & 14 & 0 \\
\hline 4 & SHTC $^{3}$ & 96 & - & Acetone & 25 & 40 & 11 & 74 & 15 & 0 \\
\hline 5 & Deloxan $^{3}$ & 70 & - & Acetone & 56 & 40 & 7 & 49 & 44 & 0 \\
\hline 6 & SHTC $^{3}$ & 96 & - & Acetone & 56 & 40 & 0 & 9 & 91 & 0 \\
\hline 7 & Deloxan & 70 & SHTC & Acetone & 0 & 70 & 0 & 83 & 17 & 0 \\
\hline 8 & Deloxan $^{3}$ & 70 & - & Acetone & 0 & 40 & 10 & 76 & 14 & 0 \\
\hline 9 & Deloxan & 70 & SHTC & Pentan-3-one & 25 & 70 & 64 & 24 & 3 & 9 \\
\hline 10 & Deloxan $^{3}$ & 70 & - & Pentan-3-one & 25 & 78 & 79 & 9 & 2 & 10 \\
\hline 11 & SHTC & 48 & Deloxan & Pentan-3-one & 25 & 78 & 41 & 39 & 4 & 16 \\
\hline 12 & SHTC & 48 & SHTC & Pentan-3-one & 25 & 78 & 44 & 35 & 13 & 8 \\
\hline 13 & SHTC & 48 & Deloxan & Pentan-3-one & 40 & 68 & 47 & 14 & 33 & 6 \\
\hline \multirow[t]{2}{*}{14} & SHTC & 48 & SHTC & Pentan-3-one & 40 & 20 & 62 & 12 & 20 & 6 \\
\hline & & & & & & 68 & 41 & 14 & 38 & 7 \\
\hline 15 & SHTC & 48 & SHTC & Pentan-3-one & 101 & 24 & 2 & 0 & 82 & 16 \\
\hline
\end{tabular}

${ }^{1}$ Reaction conditions: quinic acid (1 mmol), first acid catalyst $(0.01 \mathrm{mmol})$, ethanol $(4 \mathrm{~mL})$, reflux. After the indicated time, the catalyst was filtered off, the ethanol was evaporated under reduced pressure and the second catalyst $(0.01$ $\mathrm{mmol})$, ketone $(4 \mathrm{~mL})$ and DMP (3.5 mmol, only in the case of acetone) were added. In the case of pentan-3-one, $3 \mathrm{~mL}$ of ketone and $1 \mathrm{~mL}$ of ethanol were added in the second step, due to the lack of solubility of $4 \mathbf{b}$ in pure pentan-3-one. Temperature and time as indicated in the table; ${ }^{2}$ in the absence of DMP; ${ }^{3}$ as the two reactions were catalyzed by the same solid, the evaporation of ethanol was the only treatment after the first reaction.

Finally, the formation of the most interesting acetal-ester $3 \mathbf{b b}$ was tried by the same methodology. The ethyl quinate $4 \mathbf{b}$ was not soluble in pure pentan-3-one and a small amount of ethanol was added in the second step to allow solubilization of the substrate. At room temperature (entries 9-12), the lack of ketal in the medium and the lower reactivity of the ketone made the reaction less efficient than in the case of acetone, and the yields of $\mathbf{3} \mathbf{b} \mathbf{b}$ were low in all cases. Moreover, lactones $\mathbf{2} \mathbf{b}$ and $\mathbf{5}$ were also formed. At higher reaction temperatures (entries 13-15), the conversions were improved, but the lactonization side reaction occurred to a more significant level.

\subsection{Process at Gram Scale}

After the exploration of all the possibilities, the optimal procedure to get the acetal-ester of interest $\mathbf{3 b} \mathbf{b}$ was to use a sequential two-step process using an acid catalyst for the acetalization with pentan-3-one, with concomitant lactonization, followed by a base-catalyzed ethanolysis of the lactone in the way described in Table 5. The chosen scale was $10 \mathrm{mmol}$ of quinic acid (1.92 g) and the first reaction was carried out in pentan-3-one heated at reflux for $24 \mathrm{~h}$, with Deloxan as the catalyst. After the catalyst filtration and evaporation of the ketone, the crude product was dissolved in ethanol, cooled to $0{ }^{\circ} \mathrm{C}$ and made to react using TBD-PS as the catalyst. This reaction was monitored by ${ }^{1} \mathrm{H}$ NMR, was observed during the course of seven days, and led to a $73 \%$ yield for $3 \mathbf{b b}$. Catalyst filtration and purification by column chromatography led to $1.89 \mathrm{~g}$ of pure $3 \mathbf{b b}$ ( $66 \%$ isolated yield), and thus illustrates the potential of this methodology for preparative purposes.

Although the recovery of the catalysts was not the primary objective of the work, the gram-scale synthesis permits one to test this aspect. Moreover, the use of the sequential method allows one to recover and reuse each catalyst separately, with the possibility of optimizing the number of runs for each one $[34,35]$. In this case, both catalysts were recovered and reused under the same conditions without any further pre-treatment. The analysis of the final reaction mixture showed a yield of $57 \%$, slightly lower than in the first reaction, indicating a certain degree of deactivation. Further work would be necessary to identify the origin of this deactivation in order to optimize the recovery and reuse of this catalytic system. 


\section{Materials and Methods}

See the Supplementary Materials for a full description of the catalysts and the general reaction methods.

\subsection{Acetalization of Quinic Acid (1)}

A mixture of quinic acid $(192 \mathrm{mg}, 1 \mathrm{mmol})$ and the acid catalyst $(0.01 \mathrm{mmol})$ in acetone $(4 \mathrm{~mL})$ was heated at reflux for the required time. In some reactions, 2,2-dimethoxypropane ( $430 \mu \mathrm{L}, 364 \mathrm{mg}$, $3.5 \mathrm{mmol}$ ) was also added to the mixture. After cooling to room temperature the catalyst was filtered off and the acetone was evaporated under reduced pressure. The yield of acetal-lactone $2 \mathbf{a}$ was determined by ${ }^{1} \mathrm{H}$ NMR $[36,37]$ using mesitylene as an internal standard. The acetalization with pentan-3-one was carried out under the same conditions to obtain acetal-lactone $\mathbf{2} \mathbf{b}$ [38].

\subsection{Alcoholysis of Acetal-Lactones (2)}

A mixture of the acetal-lactone (2a or $\mathbf{2 b}, 1 \mathrm{mmol})$ and the catalyst $(0.01 \mathrm{mmol}$ of acid catalyst or $0.1 \mathrm{mmol}$ of basic catalyst) in alcohol (methanol or ethanol, $4 \mathrm{~mL}$ ) was stirred at the required temperature for the required time. After allowing the reaction to reach room temperature the catalyst was filtered off and the solvent was evaporated under reduced pressure. Yields of the different products were determined by ${ }^{1} \mathrm{H} \mathrm{NMR}$, using mesitylene as an internal standard.

\subsection{One-Pot Acetalization and Lactone Alcoholysis with a Single Acid Catalyst}

A mixture of quinic acid (192 mg, $1 \mathrm{mmol}), 2$,2-dimethoxypropane $(430 \mu \mathrm{L}, 364 \mathrm{mg}, 3.5 \mathrm{mmol})$ and the acid catalyst $(0.01 \mathrm{mmol})$ in an acetone/alcohol 1:1 (v/v) mixture $(4 \mathrm{~mL})$ was heated at reflux for $24 \mathrm{~h}$. After cooling to room temperature, the catalyst was filtered off and the acetone was evaporated under reduced pressure. Yields of the different products obtained $(2,3,4$ and 5) were determined by ${ }^{1} \mathrm{H}$ NMR, using mesitylene as an internal standard. The reaction with pentan-3-one was carried out in the same way, without 2,2-dimethoxypropane.

\subsection{One-Pot Acetalization and Lactone Alcoholysis with One Acid and One Basic Catalyst}

A mixture of quinic acid (192 mg, $1 \mathrm{mmol})$, 2,2-dimethoxypropane ( $430 \mu \mathrm{L}, 364 \mathrm{mg}, 3.5 \mathrm{mmol})$ and the acid catalyst $(0.01 \mathrm{mmol})$ in acetone $(4 \mathrm{~mL})$ was heated at reflux for $4 \mathrm{~h}$. Then the reaction mixture was cooled to $0{ }^{\circ} \mathrm{C}$, TBD-PS $(0.1 \mathrm{mmol})$ and ethanol $(4 \mathrm{~mL})$ were added and the reaction was stirred at $0{ }^{\circ} \mathrm{C}$ for at least $24 \mathrm{~h}$. The catalysts were filtered off and the solvent was evaporated under reduced pressure. Yields of the different products obtained (2a, 3ab, and $\mathbf{6})$ were determined by ${ }^{1} \mathrm{H}$ NMR using mesitylene as an internal standard. In the case of pentan-3-one, the first reaction was carried out without 2,2-dimethoxypropane and it was heated for either 24 or $48 \mathrm{~h}$. The second reaction was carried out in the same way as for acetone.

\subsection{Esterification of Quinic Acid}

A mixture of quinic acid $(192 \mathrm{mg}, 1 \mathrm{mmol})$ and the acid catalyst $(0.01 \mathrm{mmol})$ in alcohol $(4 \mathrm{~mL})$ was heated at reflux for the required time. After cooling at room temperature, the catalyst was filtered off and the solvent was evaporated under reduced pressure. Yields of ester 4 [39-41] and lactone 5 [30] were determined by ${ }^{1} \mathrm{H}$ NMR using mesitylene as an internal standard.

\subsection{Sequential Esterification and Acetalization with Two Acid Catalysts}

A mixture of quinic acid $(192 \mathrm{mg}, 1 \mathrm{mmol})$ and the acid catalyst $(0.01 \mathrm{mmol})$ in ethanol $(4 \mathrm{~mL})$ was heated at reflux for the required time. The catalyst was filtered off and the solvent was eliminated under reduced pressure. The ketone $(4 \mathrm{~mL})$ (in the case of the acetalization with pentan-3-one, $3 \mathrm{~mL}$ of pentan-3-one and $1 \mathrm{~mL}$ of EtOH$)$ and the second acid catalyst $(0.01 \mathrm{mmol})$ were added and the reaction was heated at the required temperature. 2,2-Dimethoxypropane ( $430 \mu \mathrm{L}, 364 \mathrm{mg}, 3.5 \mathrm{mmol}$ ) 
was also added when acetone was used in the acetalization step. The catalyst was filtered off and the ketone was evaporated under reduced pressure. Yields of all the products were determined by ${ }^{1} \mathrm{H}$ NMR using mesitylene as an internal standard.

\section{Conclusions}

The acetal-esters derived from quinic acid (3aa, $\mathbf{3 a b}$ and $\mathbf{3 b} \mathbf{b}$ ) can be prepared using heterogeneous catalysis through two different synthetic routes. The desired pentanone acetal ethyl ester $3 \mathbf{b b}$ has been prepared on a gram scale with an isolated yield of $66 \%$ by a sequential procedure consisting of two reaction steps: the sulfonic acid-catalyzed acetalization and the base-catalyzed alcoholysis of the acetal lactone $\mathbf{2} \mathbf{b}$. The second synthetic route involves an acid-catalyzed esterification of quinic acid followed by the acetalization, catalyzed either by the same acid or by a different solid. Although this route is effective for the isopropylidene derivative $\mathbf{3 a b}$, the acetalization with pentan-3-one is much less efficient due to the competitive lactonization under the reaction conditions. These results demonstrate the potential of heterogeneous catalysts for multistep synthesis of pharmaceutical intermediates.

Supplementary Materials: catalyst descriptions, preparation details and full spectroscopic description of compounds $2 \mathbf{a}, \mathbf{2 b}, \mathbf{3 a a}, \mathbf{3 a b}, \mathbf{3 b} \mathbf{b}, \mathbf{4 a}, \mathbf{4 b}, 5, \mathbf{6}$ and 7 , including improved assignation of ${ }^{1} \mathrm{H}$ - and ${ }^{13} \mathrm{C}-\mathrm{NMR}$ signals. It is available online at www.mdpi.com/2073-4344/7/12/393/s1.

Acknowledgments: This work was made possible by the financial support of the Spanish Ministerio de Economía y Competitividad (project CTQ2014-52367-R) and the Gobierno de Aragón (E11 Group co-financed by the European Regional Development Funds).

Author Contributions: José M. Fraile conceived and designed the experiments; Carlos J. Saavedra performed the experiments; José M. Fraile and Carlos J. Saavedra analyzed the data; José M. Fraile wrote the paper.

Conflicts of Interest: The authors declare no conflict of interest.

\section{References}

1. Federsel, H.-J. Chemical process research and development in the 21st century: Challenges, strategies, and solutions from a pharmaceutical industry perspective. Acc. Chem. Res. 2009, 42, 671-680. [CrossRef] [PubMed]

2. Wender, P.A.; Verma, V.A.; Paxton, T.J.; Pillow, T.H. Function-oriented synthesis, step economy, and drug design. Acc. Chem. Res. 2008, 41, 40-49. [CrossRef] [PubMed]

3. Newhouse, T.; Baran, P.S.; Hoffmann, R.W. The economies of synthesis. Chem. Soc. Rev. 2009, 38, 3010-3021. [CrossRef] [PubMed]

4. Clarke, P.A.; Santos, S.; Martin, W.H.C. Combining pot, atom and step economy (PASE) in organic synthesis. Synthesis of tetrahydropyran-4-ones. Green Chem. 2007, 9, 438-440. [CrossRef]

5. Vaxelaire, C.; Winter, P.; Christmann, M. One-pot reactions accelerate the synthesis of active pharmaceutical ingredients. Angew. Chem. Int. Ed. 2011, 50, 3605-3607. [CrossRef] [PubMed]

6. Climent, M.J.; Corma, A.; Iborra, S.; Sabater, M.J. Heterogeneous catalysis for tandem reactions. ACS Catal. 2014, 4, 870-891. [CrossRef]

7. Fraile, J.M.; Mallada, R.; Mayoral, J.A.; Menéndez, M.; Roldán, L. Shift of multiple incompatible equilibriums by a combination of heterogeneous catalysis and membranes. Chem. Eur. J. 2010, 16, 3296-3299. [CrossRef] [PubMed]

8. Magano, J. Synthetic approaches to the neuraminidase inhibitors zanamivir (relenza) and oseltamivir phosphate (tamiflu) for the treatment of influenza. Chem. Rev. 2009, 109, 4398-4438. [CrossRef] [PubMed]

9. Federspiel, M.; Fischer, R.; Hennig, M.; Mair, H.J.; Oberhauser, T.; Rimmler, G.; Albiez, T.; Bruhin, J.; Estermann, H.; Gandert, C.; et al. Industrial synthesis of the key precursor in the synthesis of the anti-influenza drug oseltamivir phosphate (Ro 64-0796/002, GS-4104-02): Ethyl (3R,4S,5S)-4,5-epoxy-3-(1-ethyl-propoxy)-cyclohex-1-ene-1-carboxylate. Org. Proc. Res. Dev. 1999, 3, 266-274. [CrossRef]

10. Mita, T.; Fukuda, N.; Roca, F.X.; Kanai, M.; Shibasaki, M. Second generation catalytic asymmetric synthesis of Tamiflu: Allylic substitution route. Org. Lett. 2007, 9, 259-262. [CrossRef] [PubMed] 
11. Zutter, U.; Iding, H.; Spurr, P.; Wirz, B. New, efficient synthesis of Oseltamivir phosphate (Tamiflu) via enzymatic desymmetrization of a meso-1,3-cyclohexanedicarboxylic acid diester. J. Org. Chem. 2008, 73, 4895-4902. [CrossRef] [PubMed]

12. Trost, B.M.; Zhang, T. A concise synthesis of (-)-Oseltamivir. Angew. Chem. Int. Ed. 2008, 47, 3759-3761. [CrossRef] [PubMed]

13. Yeung, Y.; Hong, S.; Corey, E.J. A short enantioselective pathway for the synthesis of the anti-influenza neuramidase inhibitor Oseltamivir from 1,3-butadiene and acrylic acid. J. Am. Chem. Soc. 2006, 128, 6310-6311. [CrossRef] [PubMed]

14. Satoh, N.; Akiba, R.; Yokoshima, S.; Fukuyama, T. A practical synthesis of (-)-Oseltamivir. Angew. Chem. Int. Ed. 2007, 46, 5734-5736. [CrossRef] [PubMed]

15. Chen, C.-A.; Fang, J.-M. Synthesis of oseltamivir and tamiphosphor from N-acetyl-D-glucosamine. Org. Biomol. Chem. 2013, 11, 7687-7699. [CrossRef] [PubMed]

16. Kongkathip, B.; Akkarasamiyo, S.; Kongkathip, N. A new and efficient asymmetric synthesis of oseltamivir phosphate (Tamiflu) from D-glucose. Tetrahedron 2015, 71, 2393-2399. [CrossRef]

17. Hayashi, Y.; Ogasawara, S. Time economical total synthesis of (-)-Oseltamivir. Org. Lett. 2016, 18, 3426-3429. [CrossRef] [PubMed]

18. Rohloff, J.C.; Kent, K.M.; Postich, M.J.; Becker, M.W.; Chapman, H.H.; Kelly, D.E.; Lew, W.; Louie, M.S.; McGee, L.R.; Prisbe, E.J.; et al. Practical total synthesis of the anti-influenza drug GS-4104. J. Org. Chem. 1998, 63, 4545-4550. [CrossRef]

19. Karpf, M.; Trussardi, R. New, azide-free transformation of epoxides into 1,2-diamino compounds: Synthesis of the anti-influenza neuraminidase inhibitor oseltamivir phosphate (tamiflu). J. Org. Chem. 2001, 66, 2044-2051. [CrossRef] [PubMed]

20. Andraos, J. Global green chemistry metrics analysis algorithm and spreadsheets: Evaluation of the material efficiency performances of synthesis plans for oseltamivir phosphate (tamiflu) as a test case. Org. Proc. Res. Dev. 2009, 13, 161-185. [CrossRef]

21. Harmer, M.A.; Sun, Q. Solid acid catalysis using ion-exchange resins. Appl. Catal. A 2001, 221, 45-62. [CrossRef]

22. Gelbard, G. Organic synthesis by catalysis with ion-exchange resins. Ind. Eng. Chem. Res. 2005, 44, 8468-8498. [CrossRef]

23. Melero, J.A.; van Grieken, R.; Morales, G. Advances in the synthesis and catalytic applications of organosulfonic-functionalized mesostructured materials. Chem. Rev. 2006, 106, 3790-3812. [CrossRef] [PubMed]

24. Chakrabarti, A.; Sharma, M.M. Cationic ion exchange resins as catalyst. React. Polym. 1993, $20,1-45$. [CrossRef]

25. Wieland, S.; Panster, P. Replacing liquid acids in fine chemical synthesis by sulfonated polysiloxanes as solid acids and as supports for precious metal catalysts. Stud. Surf. Sci. Catal. 1997, 108, 67-74. [CrossRef]

26. Harmer, M.A.; Sun, Q.; Farneth, W.E. High surface area nafion resin/silica nanocomposites: A new class of solid acid catalyst. J. Am. Chem. Soc. 1996, 118, 7708-7715. [CrossRef]

27. Fraile, J.M.; García-Bordejé, E.; Pires, E.; Roldán, L. New insights into the strength and accessibility of acid sites of sulfonated hydrothermal carbon. Carbon 2014, 77, 1157-1167. [CrossRef]

28. Fraile, J.M.; García-Bordejé, E.; Pires, E.; Roldán, L. Catalytic performance and deactivation of sulfonated hydrothermal carbon in the esterification of fatty acids: Comparison with sulfonic solids of different nature. J. Catal. 2015, 324, 107-118. [CrossRef]

29. De la Calle, C.; Fraile, J.M.; García-Bordejé, E.; Pires, E.; Roldán, L. Biobased catalyst in biorefinery processes: Sulphonated hydrothermal carbon for glycerol esterification. Catal. Sci. Technol. 2015, 5, 2897-2903. [CrossRef]

30. Sinisi, V.; Boronov, K.; Colomban, S.; Navarini, L.; Berti, F.; Forzato, C. Synthesis of mono-, di-, and tri-3,4-dimethoxycinnamoyl-1,5- $\gamma$-quinides. Eur. J. Org. Chem. 2014, 1321-1326. [CrossRef]

31. Solabannavar, S.B.; Desai, U.V.; Mane, R.B. Heck reaction in aqueous medium using Amberlite IRA-400 (basic). Green Chem. 2002, 4, 347-348. [CrossRef] 
32. Simoni, D.; Rondanin, R.; Morini, M.; Baruchello, R.; Invidiata, F.P. 1,5,7-Triazabicyclo[4.4.0]dec-1-ene (TBD), 7-methyl-TBD (MTBD) and the polymer-supported TBD (P-TBD): Three efficient catalysts for the nitroaldol (Henry) reaction and for the addition of dialkyl phosphites to unsaturated systems. Tetrahedron Lett. 2000, 41, 1607-1610. [CrossRef]

33. Soldi, L.; Ferstl, W.; Loebbecke, S.; Maggi, R.; Malmassari, C.; Sartori, G.; Yada, S. Use of immobilized organic base catalysts for continuous-flow fine chemical synthesis. J. Catal. 2008, 258, 289-295. [CrossRef]

34. Fraile, J.M.; García, N.; Herrerías, C.I.; Mayoral, J.A. Heterogeneous catalysis for tandem Mukaiyama-Michael and hydrogenation reactions: One-pot vs sequential processes. ACS Catal. 2012, 2, 56-64. [CrossRef]

35. Fraile, J.M.; García, N.; Herrerías, C.I.; Mayoral, J.A. Integration of heterogeneous catalysts into complex synthetic routes: Sequential vs.one-pot reactions in a (Knoevenagel + Mukaiyama-Michael + hydrogenation + transesterification) sequence. Catal. Sci. Technol. 2013, 3, 436-443. [CrossRef]

36. Sánchez-Abella, L.; Férnandez, S.; Armesto, N.; Ferrero, M.; Gotor, V. Novel and efficient syntheses of (-)-methyl 4-epi-shikimate and 4,5-epoxy-quinic and -shikimic acid derivatives as key precursors to prepare new analogues. J. Org. Chem. 2006, 71, 5396-5399. [CrossRef] [PubMed]

37. Baptistella, L.H.B.; Cerchiaro, G. Studies for the transformation of carbocycles into carbohydrates: Approach toward the synthesis of higher sugar derivatives. Carbohydr. Res. 2004, 339, 665-671. [CrossRef] [PubMed]

38. Lange, G.L.; Humber, C.C.; Manthorpe, J.M. [2+2] Photoadditions with chiral 2,5-cyclohexadienone synthons. Tetrahedron Asymmetry 2002, 13, 1355-1362. [CrossRef]

39. Aucktor, J.; Brückner, R. Total Synthesis of quercitols: (+)-allo-, (-)-proto-, (+)-talo-, (-)-gala-, (+)-gala-, neo-, and (-)-epi-quercitol. Synlett 2015, 26, 250-258. [CrossRef]

40. Banwell, M.G.; Hungerford, N.L.; Jolliffe, K.A. Synthesis of the sialic acid (-)-KDN and certain epimers from (-)-3-dehydroshikimic acid or (-)-quinic acid. Org. Lett. 2004, 6, 2737-2740. [CrossRef] [PubMed]

41. Zhang, W.; Zhu, X.-L.; Ding, W.; Shi, X.-X. A novel stereoselective synthesis of (-)-quinic acid starting from the naturally abundant (-)-shikimic acid. Tetrahedron Asymmetry 2015, 26, 1375-1381. [CrossRef]

(C) 2017 by the authors. Licensee MDPI, Basel, Switzerland. This article is an open access article distributed under the terms and conditions of the Creative Commons Attribution (CC BY) license (http:// creativecommons.org/licenses/by/4.0/). 